\title{
Anti-viral Effect of Bifidobacterium adolescentis against Noroviruses
}

\author{
Dan $\mathrm{Li}^{1 *}$, Adrien Breiman ${ }^{2,3,4,5}$, Jacques le Pendu ${ }^{2,3,4 \dagger}$ and Mieke Uyttendaele ${ }^{1 \dagger}$ \\ 1 Laboratory of Food Microbiology and Food Preservation, Faculty of Bioscience Engineering, Ghent University, Ghent, \\ Belgium, ${ }^{2}$ UMR 892, Institut National de la Santé et de la Recherche Médicale, Nantes, France, ${ }^{3}$ UMR 6299, Centre \\ National de la Recherche Scientifique, Nantes, France, ${ }^{4}$ Faculty of Medicine, University of Nantes, Nantes, France, ${ }^{5}$ Nantes \\ University Hospital, Nantes, France
}

OPEN ACCESS

Edited by: David Berry,

University of Vienna, Austria

Reviewed by:

Douglas Morrison,

University of Glasgow, UK

Lorena Ruiz,

Universidad Complutense de Madrid,

Spain

*Correspondence: Dan Li

dan.li@ugent.be

${ }^{\dagger}$ These authors are co-senior authors.

Specialty section: This article was submitted to Microbial Symbioses, a section of the journal Frontiers in Microbiology

Received: 23 January 2016 Accepted: 23 May 2016 Published: 08 June 2016

Citation:

Li D, Breiman A, le Pendu J and Uyttendaele M (2016) Anti-viral Effect of Bifidobacterium adolescentis against Noroviruses.

Front. Microbiol. 7:864

doi: 10.3389/fmicb.2016.00864
This study aims to investigate the effect of Bifidobacterium adolescentis against noroviruses (NoVs). Murine norovirus-1 (MNV-1) used as a surrogate was detected by plaque assay and RT-qPCR. Human NoV virus like particles (VLPS) were detected by cell-binding assay. It was shown that the presence of $B$. adolescentis could inhibit the multiplication of MNV-1 on RAW 264.7 cells within $48 \mathrm{~h}$ of co-incubation period at $37^{\circ} \mathrm{C}$. This inhibition did not occur at the viral binding stage, as no difference was observed in MNV-1 genomic copies collected from washed RAW 264.7 cells without and with $B$. adolescentis after co-incubation for $1 \mathrm{~h}$ at room temperature. Meanwhile, the presence of $B$. adolescentis decreased the binding of human NoV Gl.1 VLPs to both Caco-2 cells and HT-29 cells, while no reduction was induced for the binding of human NoV Gll.4 VLPs to Caco-2 cells.

\section{Keywords: Norovirus, Bifidobacterium adolescentis, probiotics, mechanisms}

\section{INTRODUCTION}

Probiotics are defined as "living micro-organisms, which upon ingestion in certain numbers, exert health benefits beyond inherent basic nutrition." Most probiotic microorganisms belong to lactic acid bacteria (LAB), such as Lactobacillus sp., Bifidobacterium sp., and Enterococcus sp (Ljungh and Wadström, 2006). Probiotics may benefit the human and animal host directly, by preventing the infection and combating the causative agent of the intestinal disorder, or indirectly, by balancing the disrupted equilibrium of the enteric flora and augmenting the host's immune responses (Maragkoudakis et al., 2010; Sanders et al., 2013). Clinical evidence has reported that feeding of probiotics can prevent effectively for diarrhea and shedding of rotavirus (Saavedra et al., 1994; Van Niel et al., 2002; Sazawal et al., 2006; Grandy et al., 2010). Accordingly, with the use of animal models, multiple probiotic strains have shown anti-rotavirus effect (Muñoz et al., 2011; Kandasamy et al., 2014; Mao et al., 2016). In addition, in vitro studies have demonstrated that probiotics may have antiviral activity against rotavirus (Maragkoudakis et al., 2010; Muñoz et al., 2011), coxsackievirus (Kim et al., 2014), hepatitis C virus (El-Adawi et al., 2015), as well as noroviruses (NoVs; Aboubakr et al., 2014; Rubio-del-Campo et al., 2014).

Noroviruses, one genera of the Caliciviridae family, were reported as the cause of between $73 \%$ to greater than $95 \%$ of global epidemic nonbacterial gastroenteritis outbreaks and approximately half of all gastroenteritis outbreaks (Atmar and Estes, 2006). Although NoV infections are generally mild, it may require hospital care and can be associated with mortality in elderly, chronically ill or immune-compromised patients. Taking into consideration their widespreadness, NoVs are causing heavy disease burdens associated with large economic losses (Van Beek et al., 2013). Despite recent 
progress, several key challenges remain in assessing the efficacy of vaccines and antiviral drugs for human NoV infection, such as the lack of a robust cell culture system or animal model limits direct study of these viruses, and the extreme genetic heterogeneity among strains (Karst et al., 2014). Therefore, it is of high interest to investigate further if probiotics can be employed for $\mathrm{NoV}$ control and treatment.

In this study, due to the non-cultivability of human NoVs, murine norovirus-1 (MNV-1, a very commonly used human NoV surrogate, Kniel, 2014), and human NoV virus like particles (VLPs) were used to study the effect of Bifidobacterium adolescentis against NoVs.

\section{MATERIALS AND METHODS}

\section{Bacteria}

Bifidobacterium adolescentis (LMG10502, biological origin: adult intestines) was obtained from Belgian Coordinated Collection of Microorganisms (BCCM/LMG). B. adolescentis was cultured in tryptone soya broth (TSB, Oxoid, Thermo) at $37^{\circ} \mathrm{C}$. The anaerobic atmosphere was generated with the use of ANAEROGEN $^{\mathrm{TM}}$ COMPACT (Oxoid, Thermo).

Before each experiment, B. adolescentis were cultured for $48 \mathrm{~h}$, normalized to an $\mathrm{OD}_{570}$ of 0.4 , and washed twice with phosphate buffered saline (PBS, pH 7.4).

\section{Cell Lines, Virus, and Virus-Like Particles (VLPs)}

Cells of the murine macrophage cell line RAW 264.7 (ATCC TIB-71; kindly provided by Prof. H. W. Virgin, Washington University School of Medicine, St. Louis, MO, USA) were maintained in complete DMEM medium and grown at $37^{\circ} \mathrm{C}$ under a $5 \% \mathrm{CO}_{2}$ atmosphere. Complete DMEM consisted of Dulbecco's modified Eagle's medium (DMEM; Lonza, Walkersville, MD, USA) containing 10\% low-endotoxin fetal bovine serum (HyClone, Logan, UT, USA), $100 \mathrm{U} / \mathrm{ml}$ penicillin, $100 \mu \mathrm{g} / \mathrm{ml}$ streptomycin (Lonza), $10 \mathrm{mM}$ HEPES (Lonza), and 2 mM L-glutamine (Lonza).

RAW 264.7 cells were infected with MNV-1.CW1 and passaged seven times at a multiplicity of infection (MOI) of 0.05 (MNV-1:cells) for 2 days. After two freeze-thaw cycles, low speed centrifugation was used to remove cellular debris from the virus suspension, as described by Wobus et al. (2004). The lysate containing suspended $\mathrm{MNV}-1$ was stored in aliquots at $-75^{\circ} \mathrm{C}$.

Cell line Caco-2 (ECACC 86010202) was cultured in Eagle's minimum essential medium with Earle's salts (EMEM; Lonza) supplemented with $10 \%$ low-endotoxin fetal bovine serum (HyClone), $100 \mathrm{U} / \mathrm{ml}$ penicillin, $100 \mu \mathrm{g} / \mathrm{ml}$ streptomycin (Lonza), and $2 \mathrm{mM} \mathrm{L-glutamine} \mathrm{(Lonza)} \mathrm{and} \mathrm{grown} \mathrm{at} 37^{\circ} \mathrm{C}$ under a 5\% $\mathrm{CO}_{2}$ atmosphere. HT-29 (ATCC HTB-38) cells were cultured in Dulbecco's modified Eagle's medium (DMEM; $\mathrm{GIBCO}^{\circledR}$, Life Technologies.) supplemented with $10 \%$ lowendotoxin fetal bovine serum $\left(\mathrm{GIBCO}^{\circledR}\right.$, Life Technologies), $100 \mathrm{U} / \mathrm{ml}$ penicillin, $100 \mu \mathrm{g} / \mathrm{ml}$ streptomycin $\left(\mathrm{GIBCO}^{\circledR}\right.$, Life Technologies), and $2 \mathrm{mM}$ L-glutamine $\left(\mathrm{GIBCO}^{\circledR}\right.$, Life Technologies) and grown at $37^{\circ} \mathrm{C}$ under a $5 \% \mathrm{CO}_{2}$ atmosphere.
Virus-like particles of human NoV GI.1 (Norwalk virus) and GII.4 (Dijon 1996) were generated using a previously described method (Jiang et al., 1992). Recombinant baculoviruses containing the VP1 protein from NoV GI.1 and GII.4 were generated, and VLPs were produced by infection of Hi5 insect cells. VLPs were released from the infected Hi5 cells by three rounds of freeze-thawing and then clarified by removal of cellular debris $(6,000 \times \mathrm{g}$ for $30 \mathrm{~min})$ and baculovirus $(14,000 \times \mathrm{g}$ for $30 \mathrm{~min})$. The VLPs were partially purified through a $30 \%$ (wt/vol) sucrose cushion in TNC buffer $(50 \mathrm{mM}$ Tris- $\mathrm{HCl}, \mathrm{pH}$ 7.4, $150 \mathrm{mM} \mathrm{NaCl}, 10 \mathrm{mM} \mathrm{CaCl} 2$ ) containing the protease inhibitor leupeptin at $150,000 \times \mathrm{g}$ for $2 \mathrm{~h}$. The pelleted VLPs were resuspended in TNC and further purified by isopynic centrifugation in cesium chloride $(150,000 \times g ; 18 \mathrm{~h})$. The resultant VLP bands were collected by puncture, and the solution containing VLPs was dialyzed against PBS prior to quantification by bicinchoninic acid (BCA) protein assay (Thermo Scientific) and stored at $-80^{\circ} \mathrm{C}$.

\section{Cytotoxicity Test-Neutral Red Assay}

The cytotoxicity of bacteria on RAW 264.7 cells was measured by a neutral red assay based on the description by Fotakis and Timbrell (2006) with a few modifications. The RAW 264.7 cells were seeded into 96-well plates at a density of $10^{5}$ viable cells per well. On the following day, the RAW 264.7 cells were washed with PBS to remove the antibiotics, the $B$. adolescentis re-suspended in DMEM (Lonza) were added onto the cells (50 $\mu \mathrm{l}$ per well) and incubated for $1 \mathrm{~h}$ at room temperature. Afterward the inoculum was aspirated and fresh complete DMEM without antibiotics was added (100 $\mu \mathrm{l}$ per well). Plates were incubated at $37^{\circ} \mathrm{C}$ and $5 \%$ $\mathrm{CO}_{2}$.

After 2 days incubation, the medium of the cells was changed to neutral red dye (Sigma-Aldrich, St. Louis, MO, USA, $100 \mu \mathrm{g} / \mathrm{ml})$ dissolved in DMEM (100 $\mu$ l per well) and incubated for another $2 \mathrm{~h}$ at $37^{\circ} \mathrm{C}$ and $5 \% \mathrm{CO}_{2}$. Cells were then washed with PBS and the addition of elution medium (EtOH/AcCOOH, $50 \% / 1 \%, 100 \mu \mathrm{l}$ per well) followed by gentle shaking for $10 \mathrm{~min}$ so that complete dissolution was achieved. The optical density was read at $540 \mathrm{~nm}\left(\mathrm{OD}_{540}\right)$.

\section{Viral Multiplication Inhibition Test on MNV-1 Detected by Plaque Assay}

The RAW 264.7 cells were seeded into six-well plates at a density of $2 \times 10^{6}$ viable cells per well. On the following day, the B. adolescentis re-suspended in DMEM (Lonza) was used to make ten-fold dilutions from MNV-1 lysate. The RAW 264.7 cells were washed with PBS to remove the antibiotics, the mixture of bacteria and MNV-1 was added onto the cells (500 $\mu$ l per well, two wells per sample). Plates were incubated for $1 \mathrm{~h}$ at room temperature and manually rocked every $15 \mathrm{~min}$ before aspirating the inoculum and overlaying the cells with $1.5 \%$ SeaPlaque agarose (Cambrex, Rockland, ME, USA) in MEM (Lonza) supplemented with $10 \%$ low-endotoxin fetal bovine serum, $1 \%$ HEPES, $1 \%$ penicillin/streptomycin, and $2 \%$ glutamine (complete MEM) per well. Plates were incubated at $37^{\circ} \mathrm{C}$ and $5 \% \mathrm{CO}_{2}$ for 2 days. To visualize plaques, cells were stained with $1.5 \%$ 
SeaKem agarose in complete MEM containing $1 \%$ neutral red (Sigma-Aldrich) per well for $6 \mathrm{~h}$.

Plaque sizes were shown to be associated with the virulence in multiple studies (Takemoto, 1966; Lipton, 1980). In this study, from photos taken from each group with the same format and size, the diameters of plaques were measured and recorded by the use of Image (National Institutes of Health, Bethesda, MD, USA).

\section{Viral Binding Inhibition Test on MNV-1 Detected by RT-qPCR}

The RAW 264.7 cells were seeded into 96-well plates at a density of $10^{5}$ viable cells per well. On the following day, the $B$. adolescentis was re-suspended in MNV-1 dilutions with DMEM (50 $\mu \mathrm{l}$ per sample, with $5.8 \pm 0.1 \log \mathrm{MNV}-1$ genomic copies per sample). The RAW 264.7 cells were washed with PBS to remove the antibiotics, the mixture of bacteria and MNV-1 were added onto the cells $(50 \mu \mathrm{l}$ per well) and incubated for $1 \mathrm{~h}$ at room temperature. Afterward the inoculum was aspirated and the cells were washed by PBS for three times.

The RNAs of washed cells were extracted by using the RNeasy Mini kit (Qiagen, Hilden, Germany). For each sample the $100 \mu \mathrm{l}$ PBS was firstly mixed with $350 \mu$ l lysis buffer, and the mixture was pipetted back onto the cells in the 96-well plates in order to lyse the cells. The following procedures were performed according to the RNA Cleanup protocol and the RNA were stored at $-75^{\circ} \mathrm{C}$.

The RT-qPCR of MNV-1 was performed by the use of RNA UltraSense ${ }^{\mathrm{TM}}$ One-Step Quantitative RT-PCR System (Life technologies). The primers and probe sequence of MNV-1 were previously shown by Baert et al. (2008). Twenty micro liter of reaction mixture [200 nM each primer, $200 \mathrm{nM}$ probe, $50 \mathrm{nM}$ ROX (Life technologies)] was added to $5 \mu \mathrm{l}$ of RNA. The RTqPCR assays were performed in an ABI 7300 system (Applied Biosystems). The amplification profile consisted of $50^{\circ} \mathrm{C}$ for $15 \mathrm{~min}, 95^{\circ} \mathrm{C}$ for $2 \mathrm{~min}$ and $45 \mathrm{cycles}$ of $95^{\circ} \mathrm{C}$ for $15 \mathrm{~s}$ and $60^{\circ} \mathrm{C}$ for $30 \mathrm{~s}$.

An absolute quantification of MNV-1 genomic copies was performed as described by Baert et al. (2008). To obtain representative positive control standards, the plasmid p20.3 containing a full-length cDNA clone of MNV-1.CW1 (Baert et al., 2008) was used for the quantifications. Ten-fold serial dilutions ranging from $10^{6}$ to 10 copies of plasmids per reaction were used to prepare the standard curves.

\section{Viral Binding Inhibition Test on Human NoV VLPs Detected by Fluorescence Measurement}

The HT-29 cells were seeded into 96-well plates at a density of $10^{5}$ viable cells per well. On the following day, the B. adolescentis was re-suspended in NoV GI.1 VLP suspension [5 $\mu \mathrm{g} / \mathrm{ml}$, in PBS$0.1 \%$ bovine serum albumin (BSA)]. The mixture of bacteria and VLPs was added onto the cells $(50 \mu \mathrm{l}$ per well) and incubated for $1 \mathrm{~h}$ at room temperature. After washing with PBS for three times, the cells were fixed with $4 \%$ paraformaldehyde, and stained by anti-VLP rabbit polyclonal antibodies (lp130 for GI.1, diluted in PBS-0.1\% BSA, 1-h incubation at $37^{\circ} \mathrm{C}$ ) followed by
Alexa Fluor ${ }^{\circledR} 488$ Goat Anti-Rabbit IgG $(\mathrm{H}+\mathrm{L})$ antibody (Life Technologies, diluted in PBS-0.1\% BSA, 1-h incubation at $37^{\circ} \mathrm{C}$ ). Three times washing by PBS was always performed after each step. The fluorescence was read by a fluorimeter (Fluoroskan, Thermo Scientific; $\mathrm{Ex} / \mathrm{Em}=490 / 525 \mathrm{~nm}$ ) in arbitrary unit (a.u.).

The binding test of human NoV GI.1 and GII.4 VLPs (antiVLP rabbit polyclonal antibodies lp130 for GI.1 and lp132 for GII.4) on Caco-2 cell were similar with the procedures above except that the Caco-2 cells were incubated for 21 days post confluency to be used as differentiated cells.

The binding of NoV GI.1 VLPs to HT-29 cells was also observed with a fluorescence microscope. The HT-29 cells were seeded into eight-well Nunc ${ }^{\circledR}$ Lab-Tek $^{\circledR}$ Chamber Slide System (Sigma-Aldrich) at a density of $10^{5}$ viable cells per well. On the following day, the binding and staining steps were the same as described above. After the last washing step (from the secondary antibody incubation), the upper structure was removed from the bottom glass slide. The stained cells were mounted on slides with Vectashield $^{\circledR}$ (Vector laboratories, Burlingame, CA, USA). The sealed slides were observed under a Zeiss Axiovert 200 fluorescence microscope.

\section{Data Analysis}

Each result was presented as the mean value of three independent replicates with the standard deviation. Statistical analyses were performed by Mann-Whitney $U$ test with SPSS 22 for Windows (SPSS, Inc., Chicago, IL, USA). Significant differences were considered when $P$ was $<0.05$.

\section{RESULTS}

\section{Effect of B. adolescentis on MNV-1 Infectivity}

First of all, after $48 \mathrm{~h}$ incubation, the cell viability determined by neutral red assay showed no significant reduction after incubation of the RAW 264.7 cells with B. adolescentis $\left(\mathrm{OD}_{540}\right.$ $1.1 \pm 0.1-1.1 \pm 0.2, P>0.05)$.

MNV-1 lysate was diluted to a concentration that can form countable plaques on the six-well plates, and was seeded onto the cells with or without $B$. adolescentis. The plaque assay showed that compared with the negative control (MNV-1 on RAW 264.7 cells without bacteria), the MNV-1 plaque forming units (PFU) from cell-culture wells in the presence of $B$. adolescentis were decreased significantly from $20 \pm 3-7 \pm 2$ PFU/well (Figure 1A, $P<0.05$ ).

It was also noticed that the sizes of the plaques from cells incubated with $B$. adolescentis were smaller than the negative control (examples shown in Figure 1C). The average sizes of the plaques measured by ImageJ showed that compared with the negative control (MNV-1 on RAW 264.7 cells without bacteria), the plaque diameters from cell-culture wells in the presence of $B$. adolescentis were decreased significantly from $9.2 \pm 2.7-$ $3.9 \pm 0.6$ pixel (Figure 1B, $P<0.05$ ). These results indicate that the effect of $B$. adolescentis on MNV-1 may occur mainly in the viral replication phase instead of showing direct virucidal effect on the MNV-1 or preventing the viruses from binding to the cells. 
A

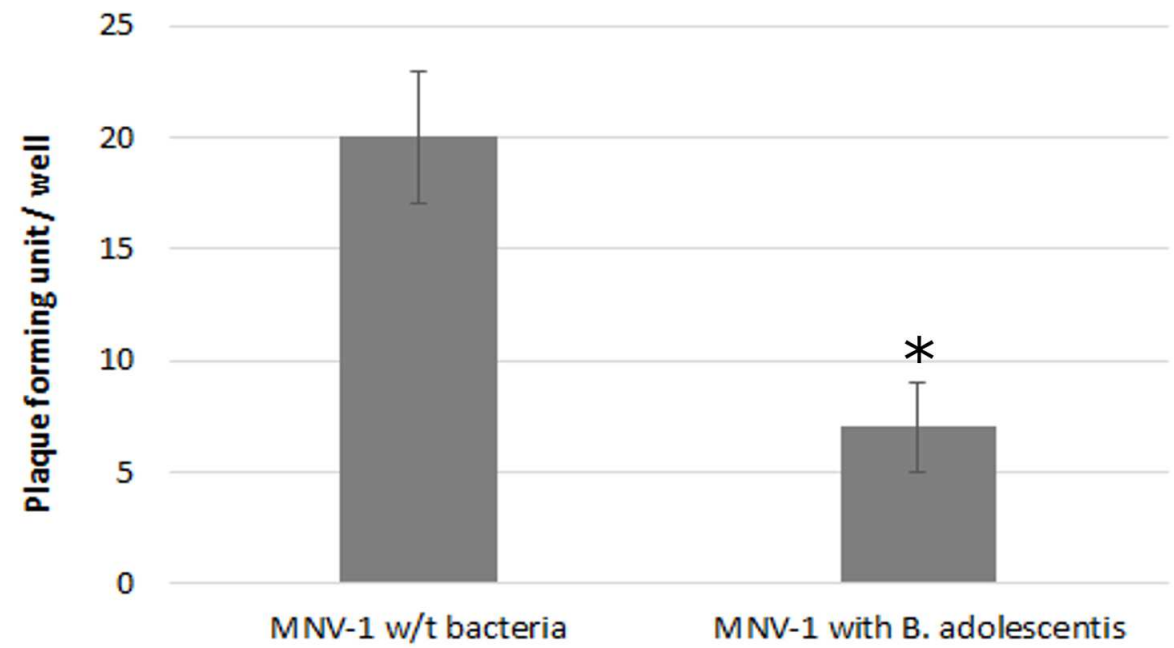

B

14

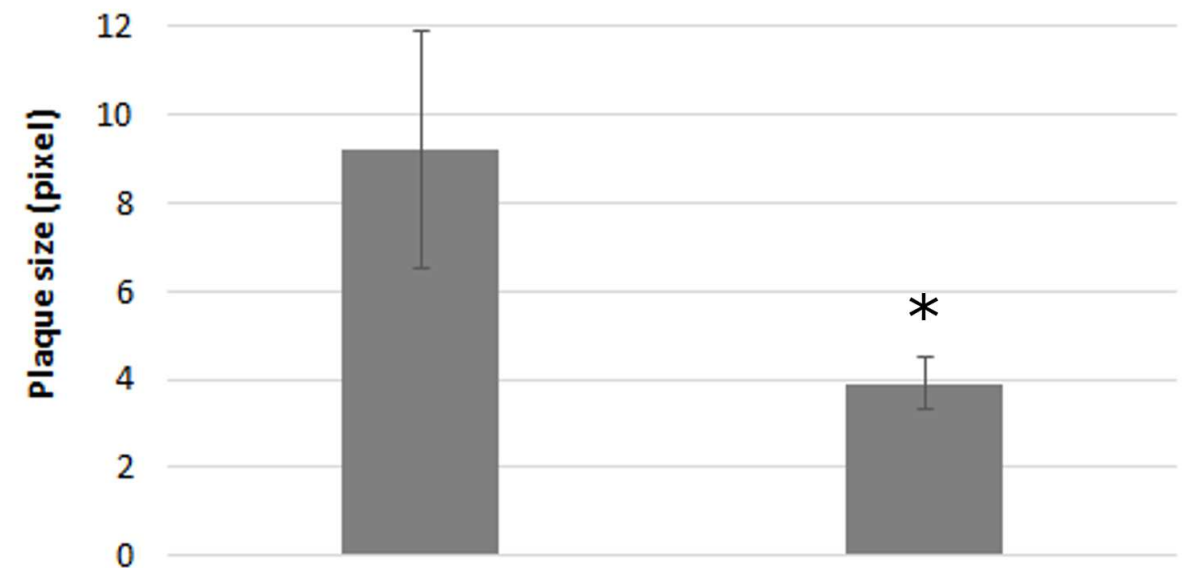

MNV-1 w/t bacteria

MNV-1 with B. adolescentis

C

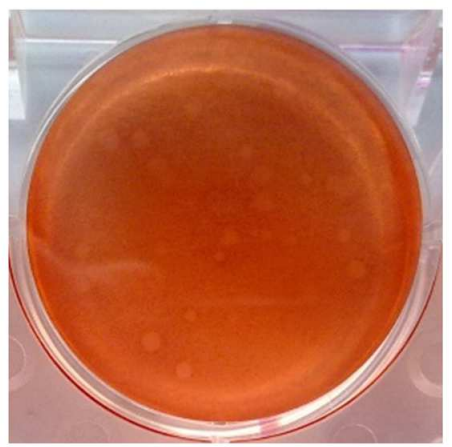

MNV-1 w/t bacteria

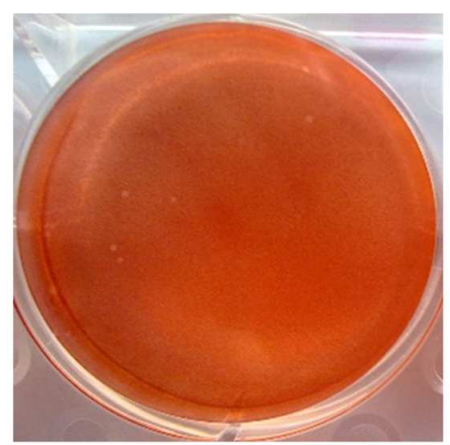

MNV-1 with $B$. adolescentis

FIGURE 1 | MNV-1 multiplication inhibition by B. adolescentis determined by plaque assay. (A) Plaque forming units (PFU) from cell-culture wells with and without $B$. adolescentis. Each data point is an average of three independent tests, and each error bar represents the data range. ${ }^{*} P<0.05$. (B) Plaque diameters from cell-culture wells with and without $B$. adolescentis. Each data point is an average of 15 measurements, and each error bar represents the data range. $* P<0.05$. (C) Plaque appearances from cell-culture wells with and without $B$. adolescentis. 
Therefore lastly, a viral binding inhibition test was performed and indeed no significant difference of MNV-1 genomic copies collected from RAW 264.7 cells between the two groups with $(5.77 \pm 0.03$ log-genomic copies $/ \mathrm{ml})$ and without $B$. adolescentis $(5.74 \pm 0.01 \mathrm{log}$-genomic copies $/ \mathrm{ml})$ was observed $(P>0.05)$.

\section{Effect of $B$. adolescentis on Human NoV VLPs Cell-Binding Ability}

It has been previously reported that both VLPs of human NoV GI.1 and GII.4 could bind to Caco- 2 cells (Tamura et al., 2004) and VLPs of human NoV GI.1 could bind to HT-29 cells (Rubiodel-Campo et al., 2014).

The presence of $B$. adolescentis decreased the binding of human NoV GI.1 VLPs to Caco-2 cells, measured by fluorescence intensity, significantly from $45.2 \pm 5.0$ (negative control without bacteria) to $33.0 \pm 4.6$ a.u. (incubation with $B$. adolescentis; Figure 2A, $P<0.05)$.

The fluorescence intensity of human NoV GI.1 VLPs on HT-29 cells also decreased, although not significantly, from $92.0 \pm 25.0$ to $52.0 \pm 5.0$ a.u. by the incubation of $B$. adolescentis (Figure 2B, $P=0.05$ ). A visual example detected by fluorescence microscopy was shown in Figure 2C.

As for human NoV GII.4 VLPs, no significant reduction was observed for the binding of the VLPs to Caco-2 cells with the incubation of $B$. adolescentis (19.0 \pm 1.7 to $17.7 \pm 0.6$ a.u., $P>0.05)$.

\section{DISCUSSION}

Currently, the research on the effect of probiotics on NoVs are still preliminary. On one hand, due to the non-cultivability of human NoVs, the in vitro studies were conducted with the use of surrogate viruses [e.g., feline calicivirus (FCV), Aboubakr et al., 2014; MNV-1 and Tulane virus (TV), Shearer et al., 2014] and artificially synthesized particles partially mimicking the viral structures ( $P$-particles, Rubio-del-Campo et al., 2014), which may introduce gaps from the authentic NoV reactions. On the other hand, there are an insufficient number of indepth studies on this topic before a general conclusion can be drawn. For instance, it was reported that the fermentation of Donchimi and oysters could effectively reduce the infectivity of FCV and MNV-1 (Lee et al., 2012; Seo et al., 2014). The population of LAB increased largely during the fermentation, however, it was neither clear on the role that the LAB played nor the associated mechanisms (Lee et al., 2012; Seo et al., 2014). For another instance, high infectivity reduction (6 -7log reduction) was observed for FCV following co-incubation with Lactococcus lactis (both bacterial medium filtrate and cells suspension, Aboubakr et al., 2014). However, the cell-free supernatant of a commercial probiotic mixture of Lactobacillus acidophilus, Lactobacillus rhamnosus, Bifidobacterium bifidum, Lactobacillus salivarius, and Streptococcus thermophiles indicated no reduction for the infectivity of MNV and TV (Shearer et al., 2014). The reasons causing the inconsistence of the studies can be the differences between both of the studied viruses and bacteria strains, as well as the experimental settings such as time/sequence

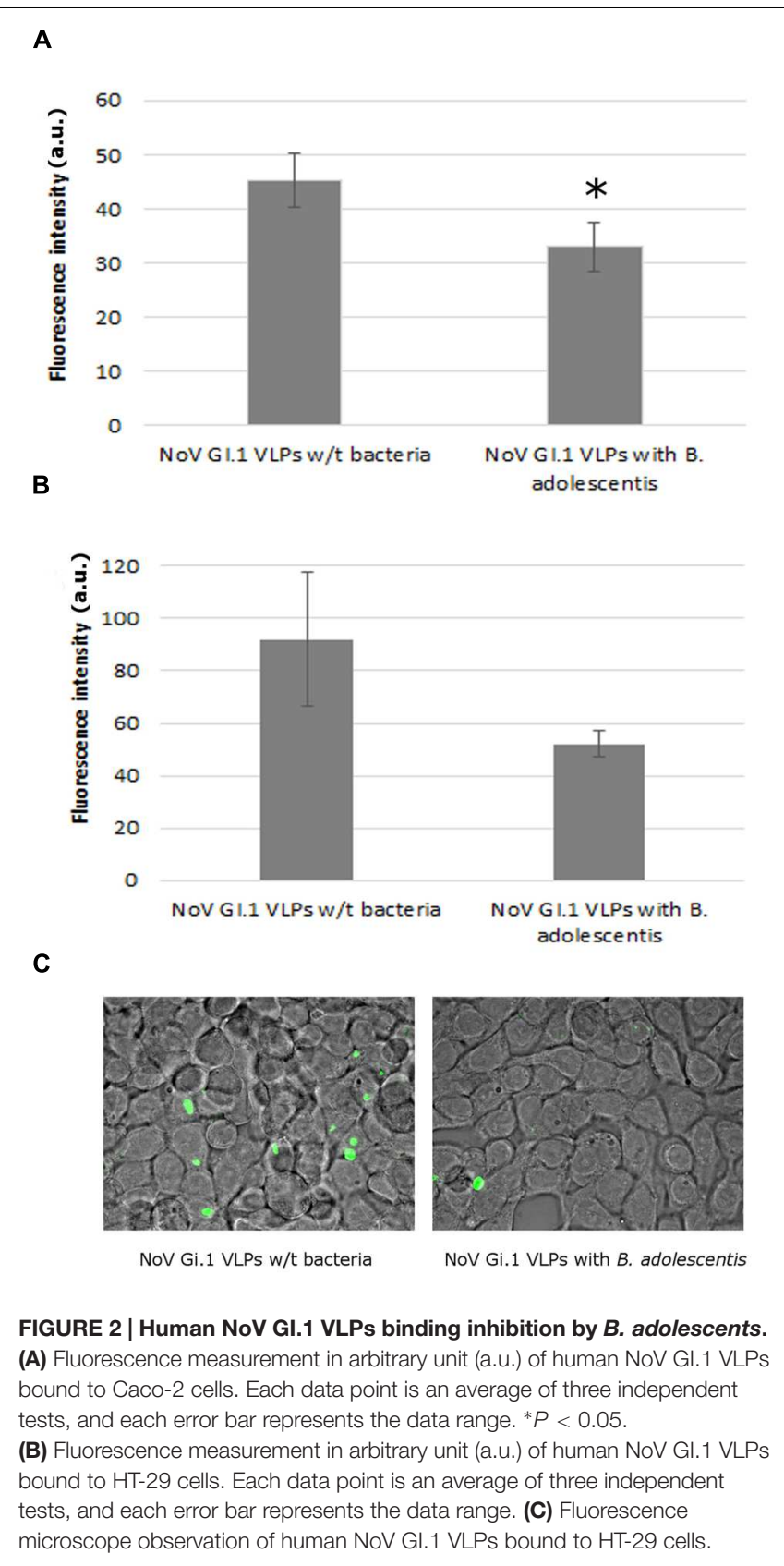

of addition, comparative ratio of viruses and bacteria, incubation conditions (time, atmosphere and temperature) and matrices, etc.

In this study, MNV-1 was employed as the surrogate as it was more persistent than FCV in the fermentation of both Donchimi and oysters (Lee et al., 2012; Seo et al., 2014). Human NoV VLPs from GI.1 and GII.4 were used as they could mimic the binding capacity of two representative NoV genotypes. B. adolescentis is a recognized probiotics (Lee et al., 1993; Kim et al., 2008) and has interested dairy manufacturers in producing "therapeutic fermented milk products” (Arunachalam, 1999; Puniya, 2015). Also it was reported recently to exhibit antiviral activity against Coxsackievirus (Kim et al., 2014). The bacterial cells were washed 
with PBS before being added to the viruses and cells in order to avoid any direct virucidal effect of the bacterial metabolites in the culture medium, such as organic acids, diacetyl, and bacteriocins. The bacteria and viruses (MNV-1 and human NoV VLPs) were co-incubated with the cells as this strategy was shown to be more effective than pre-treatment of cells, pre-treatment of viruses (Aboubakr et al., 2014; Rubio-del-Campo et al., 2014), or posttreatment of cells attached to viruses (Rubio-del-Campo et al., 2014).

It was demonstrated in this study that the presence of $B$. adolescentis could inhibit the multiplication of MNV-1 on RAW 264.7 cells. Meanwhile, it was shown that this inhibition effect did not occur on the binding stage of MNV-1 to RAW 264.7 cells. However, in contrast, the presence of B. adolescentis did decrease the binding of human NoV GI.1 VLPs to both Caco2 cells and HT-29 cells. Although based on different models, these results indicate that the effects of $B$. adolescentis on different viruses might vary based on different mechanisms.

It was reported previously that NoV P-particles could bind to a series of probiotics with varied binding ability, which was postulated as one of the antiviral mechanisms of the probiotics (Rubio-del-Campo et al., 2014). However, based on a recent study of our group (Li et al., 2015), the B. adolescentis strain used in this study does not express histo-blood group antigen (HBGA) and could not bind to NoV VLPs of either GI.1 or GII.4. This result rules out the possibility of direct competition of B. adolescentis and NoV GI.1VLPs from binding to Caco-2 or HT-29 cells. Instead, as we and others have described a few bacterial lectins binding to HBGAs (Gilboa-Garber et al., 2011; Audfray et al., 2012) and Zhong et al. (2004) have reported that the adhesin of $B$. adolescentis 1027 could inhibit the adhesion of Escherichia coli to intestinal epithelial cell line Lovo, we assume that certain lectins secreted by $B$. adolescentis could bind to the HBGAs on the intestinal cell lines and compete with the binding of NoV GI.1VLPs.

As the binding of human NoV GI.1 VLPs to both Caco-2 cells and HT-29 cells was decreased in the presence of B. adolescentis, it is reasonable to assume that the viral multiplication of human NoV GI.1, if an in vitro model could be established, should also be decreased in the presence of $B$. adolescentis. On the other hand, although no reduction of the binding of human NoV GII.4 VLPs to Caco-2 cells was observed in the presence of $B$. adolescentis, the possibility cannot be ruled out that $B$. adolescentis may reduce the viral multiplication of human NoV GII.4 if an in vitro model could be established, or help combat NoVs in vivo. The differences observed between the two strains are not surprising as it is well known that the chemical

\section{REFERENCES}

Aboubakr, H. A., El-Banna, A. A., Youssef, M. M., Al-Sohaimy, S. A., and Goyal, S. M. (2014). Antiviral effects of Lactococcus lactis on feline calicivirus, a human norovirus surrogate. Food Environ. Virol. 6, 282-289. doi: 10.1007/s12560-0149164-2

Arunachalam, K. D. (1999). Role of bifidobacteria in nutrition, medicine and technology. Nutrition Res. 19, 1559-1597. doi: 10.1016/j.anaerobe.2015. 05.012 structures of the receptor binding interfaces are different between NoV GI.1 and GII.4 (Tan and Jiang, 2011). However, the exact molecular mechanisms casing the influence of $B$. adolescentis on human NoV VLPs binding to intestinal cell lines still need further investigation.

\section{CONCLUSION}

This study demonstrated the antiviral effect of $B$. adolescentis against NoVs. Due to the lack of models to study the infection of genuine human NoVs, the results were generated from studying surrogates detected by different methods (infection and binding of MNV-1 on murine macrophage cell line RAW 264.7and binding of human NoV VLPs on human intestinal epithelial cell lines Caco-2 and HT-29). Since the effects of B. adolescentis on MNV-1 and human NoV VLPs as well as their mechanisms were indicated to be different, this study shows the importance of establishing multiplication model for human NoVs in the future. In addition, more probiotic strains will be tested before a general conclusion can be drawn on the antiviral effect of probiotics on NoV infection.

\section{AUTHOR CONTRIBUTIONS}

DL performed most of the experiments and composed the manuscript. AB supplied technical support for the experiments, especially for the fluorescence microscope as well as improvement of the manuscript. JP and MU gave strategic guidance for the work and suggestions to improve the manuscript.

\section{FUNDING}

This study was supported by a postdoctoral grant (DL.) and a financial support for staying abroad (DL.) from the Research Foundation-Flanders (Fonds voor Wetenschappelijk OnderzoekVlaanderen) and by a grant from the Region des Pays de la Loire (ARMINA).

\section{ACKNOWLEDGMENT}

The authors also acknowledge the help of imaging core facilities of the University of Nantes (Micropicell).

Atmar, R. L., and Estes, M. K. (2006). The epidemiologic and clinical importance of norovirus infection. Gastroenterol. Clin. North Am. 35, 275-290. doi: 10.1016/j.gtc.2006.03.001

Audfray, A., Claudinon, J., Abounit, S., Ruvoën-Clouet, N., Larson, G., Smith, D. F., et al. (2012). Fucose-binding lectin from opportunistic pathogen Burkholderia ambifaria binds to both plant and human oligosaccharidic epitopes. J. Biol. Chem. 287, 4335-4347. doi: 10.1074/jbc.M111.314831

Baert, L., Wobus, C. E., Van Coillie, E., Thackray, L. B., Debevere, J., and Uyttendaele, M. (2008). Detection of murine norovirus 1 by using 
plaque assay, transfection assay, and real-time reverse transcription-PCR before and after heat treatment. Appl. Environ. Microbiol. 74, 543-546. doi: 10.1128/AEM.01039-07

El-Adawi, H., Nour, I., Fattouh, F., and El-Deeb, N. (2015). Investigation of the antiviral bioactivity of Lactobacillus bulgaricus $761 \mathrm{~N}$ extracellular extract against hepatitis C virus (HCV). Int. J. Pharm. 11, 19-26. doi: 10.3923/ijp.2015.19.26

Fotakis, G., and Timbrell, J. A. (2006). In vitro cytotoxicity assays: comparison of LDH, neutral red, MTT and protein assay in hepatoma cell lines following exposure to cadmium chloride. Toxicol. Lett. 160, 171-177.

Gilboa-Garber, N., Zinger-Yosovich, K. D., Sudakevitz, D., Lerrer, B., Imberty, A., Wimmerova, M., et al. (2011). "The five bacterial lectins (PA-IL, PA-IIL, RSL, RS-IIL, and CV-IIL): interactions with diverse animal cells and glycoproteins," in The Molecular Immunology of Complex Carbohydrates-3, ed. A. M. Wu (New York, NY: Springer), 155-211.

Grandy, G., Medina, M., Soria, R., Terán, C. G., and Araya, M. (2010). Probiotics in the treatment of acute rotavirus diarrhoea. A randomized, double-blind, controlled trial using two different probiotic preparations in Bolivian children. BMC Infect. Dis. 10:253. doi: 10.1186/1471-2334-10-253

Jiang, X., Wang, M., Graham, D. Y., and Estes, M. K. (1992). Expression, selfassembly, and antigenicity of the Norwalk virus capsid protein. J. Virol. 66, 6527-6532.

Kandasamy, S., Chattha, K. S., Vlasova, A. N., Rajashekara, G., and Saif, L. J. (2014). Lactobacilli and Bifidobacteria enhance mucosal B cell responses and differentially modulate systemic antibody responses to an oral human rotavirus vaccine in a neonatal gnotobiotic pig disease model. Gut Microbes 5, 639-651. doi: 10.4161/19490976.2014.969972

Karst, S. M., Wobus, C. E., Goodfellow, I. G., Green, K. Y., and Virgin, H. W. (2014). Advances in norovirus biology. Cell Host Microbe 15, 668-680. doi: 10.1016/j.chom.2014.05.015

Kim, M. J., Lee, D. K., Park, J. E., Park, I. H., Seo, J. G., and Ha, N. J. (2014). Antiviral activity of Bifidobacterium adolescentis SPM1605 against Coxsackievirus B3. Biotechnol. Biotechnol. Equip. 28, 681-688. doi: 10.1080/13102818.2014.945237

Kim, Y., Lee, D., Kim, D., Cho, J., Yang, J., Chung, M., et al. (2008). Inhibition of proliferation in colon cancer cell lines and harmful enzyme activity of colon bacteria by Bifidobacterium adolescentis SPM0212. Arch. Pharm. Res. 31, 468-473. doi: 10.1007/s12272-001-1180-y

Kniel, K. E. (2014). The makings of a good human norovirus surrogate. Curr. Opin. Virol. 4, 85-90. doi: 10.1016/j.coviro.2014.01.002

Lee, J., Ametani, A., Enomoto, A., Sato, Y., Motoshima, H., Ike, F., et al. (1993). Screening for the immunopotentiating activity of food microorganisms and enhancement of the immune response by Bifidobacterium adolescentis M101-4. Biosci. Biotechnol. Biochem. 57, 2127-2132. doi: 10.1271/bbb.57.2127

Lee, M. H., Yoo, S.-H., Ha, S.-D., and Choi, C. (2012). Inactivation of feline calicivirus and murine norovirus during Dongchimi fermentation. Food Microbial. 31, 210-214. doi: 10.1016/j.fm.2012.04.002

Li, D., Breiman, A., Le Pendu, J., and Uyttendaele, M. (2015). Binding to histoblood group antigen-expressing bacteria protects human norovirus from acute heat stress. Front. Microbiol. 6:659. doi: 10.3389/fmicb.2015.00659

Lipton, H. L. (1980). Persistent theiler's murine encephalomyelitis virus infection in mice depends on plaque Size. J. Gen. Virol. 46, 169-177. doi: 10.1099/00221317-46-1-169

Ljungh, A., and Wadström, T. (2006). Lactic acid bacteria as probiotics. Curr. Issues Intest. Microbiol. 7, 73-90.

Mao, X., Gu, C., Hu, H., Tang, J., Chen, D., Yu, B., et al. (2016). Dietary Lactobacillus rhamnosus GG supplementation improves the mucosal barrier function in the intestine of weaned piglets challenged by porcine rotavirus. PLOS ONE 11:e0146312. doi: 10.1371/journal.pone.01 46312

Maragkoudakis, P. A., Chingwaru, W., Gradisnik, L., Tsakalidou, E., and Cencic, A. (2010). Lactic acid bacteria efficiently protect human and animal intestinal epithelial and immune cells from enteric virus infection. Int. J. Food Microbiol. 141, S91-S97. doi: 10.1016/j.ijfoodmicro.2009.12.024
Muñoz, J. A. M., Chenoll, E., Casinos, B., Bataller, E., Ramón, D., Genovés, S., et al. (2011). Novel probiotic Bifidobacterium longum subsp. infantis CECT 7210 strain active against rotavirus infections. Appl. Environ. Microbiol. 77, 8775-8783. doi: 10.1128/AEM.05548-11

Puniya, A. K. (2015). Fermented Milk and Dairy Products. Boca Raton, FL: CRC Press, 105.

Rubio-del-Campo, A., Coll-Marqués, J. M., Yebra, M. J., Buesa, J., PérezMartínez, G., Monedero, V., et al. (2014). Noroviral p-particles as an in vitro model to assess the interactions of noroviruses with probiotics. PLoS ONE 9:e89586. doi: 10.1371/journal.pone.0089586

Saavedra, J. M., Bauman, N., Perman, J., Yolken, R., and Oung, I. (1994). Feeding of Bifidobacterium bifidum and Streptococcus thermophilus to infants in hospital for prevention of diarrhoea and shedding of rotavirus. Lancet 344, 1046-1049. doi: 10.1016/S0140-6736(94)91708-6

Sanders, M. E., Guarner, F., Guerrant, R., Holt, P. R., Quigley, E. M., Sartor, R. B., et al. (2013). An update on the use and investigation of probiotics in health and disease. Gut 62, 787-796. doi: 10.1136/gutjnl-2012-302504

Sazawal, S., Hiremath, G., Dhingra, U., Malik, P., Deb, S., and Black, R. E. (2006). Efficacy of probiotics in prevention of acute diarrhoea: a meta-analysis of masked, randomised, placebo-controlled trials. Lancet Infect. Dis. 6, 374-382. doi: 10.1016/S1473-3099(06)70495-9

Seo, D. J., Lee, M. H., Seo, J., Ha, S.-D., and Choi, C. (2014). Inactivation of murine norovirus and feline calicivirus during oyster fermentation. Food Microbiol. 44, 81-86. doi: 10.1016/j.fm.2014.05.016

Shearer, A. E., Hoover, D. G., and Kniel, K. E. (2014). Effect of bacterial cell-free supernatants on infectivity of norovirus surrogates. J. Food Protect. 77, 145-149. doi: 10.4315/0362-028X.JFP-13-204

Takemoto, K. K. (1966). Plaque mutants of animal viruses. Prog. Med. Virol. 8, 314-348.

Tamura, M., Natori, K., Kobayashi, M., Miyamura, T., and Takeda, N. (2004). Genogroup II noroviruses efficiently bind to heparin sulfate proteoglycan associated with the cellular membrane. J. Virol. 78, 3817-3826. doi: 10.1128/JVI.78.8.3817-3826.2004

Tan, M., and Jiang, X. (2011). Norovirus-host interaction: multi-selections by human histo-blood group antigens. Trends Microbiol. 19, 382-388. doi: 10.1016/j.tim.2011.05.007

Van Beek, J., Ambert-Balay, K., Botteldoorn, N., Eden, J., Fonager, J., Hewitt, J., et al. (2013). Indications for worldwide increased norovirus activity associated with emergence of a new variant of genotype II. 4, late 2012. Euro Surveill. $18,8-9$.

Van Niel, C. W., Feudtner, C., Garrison, M. M., and Christakis, D. A. (2002). Lactobacillus therapy for acute infectious diarrhea in children: a meta-analysis. Pediatrics 109:e52. doi: 10.1542/peds.109.4.678

Wobus, C. E., Karst, S. M., Thackray, L. B., Chang, K., Sosnovtsev, S. V., Belliot, G., et al. (2004). Replication of norovirus in cell culture reveals a tropism for dendritic cells and macrophages. PLoS Biol. 2:e432. doi: 10.1371/journal.pbio.0020432

Zhong, S.-S., Zhang, Z.-S., Wang, J.-D., Lai, Z.-S., Wang, Q.-Y., Pan, L.-J., et al. (2004). Competitive inhibition of adherence of enterotoxigenic Escherichia coli, enteropathogenic Escherichia coli and Clostridium difficile to intestinal epithelial cell line Lovo by purified adhesin of Bifidobacterium adolescentis 1027. World J. Gastroenterol. 10, 1630-1633. doi: 10.3748/wjg.v10.i11.1630

Conflict of Interest Statement: The authors declare that the research was conducted in the absence of any commercial or financial relationships that could be construed as a potential conflict of interest.

Copyright (c) 2016 Li, Breiman, le Pendu and Uyttendaele. This is an open-access article distributed under the terms of the Creative Commons Attribution License (CC BY). The use, distribution or reproduction in other forums is permitted, provided the original author(s) or licensor are credited and that the original publication in this journal is cited, in accordance with accepted academic practice. No use, distribution or reproduction is permitted which does not comply with these terms. 